\title{
Electrical Characterization of Amorphous Silicon MIS-Based Structures for HIT Solar Cell Applications
}

\author{
Héctor García', Helena Castán ${ }^{1 *}$, Salvador Dueñas ${ }^{1}$, Luis Bailón, Rodrigo García-Hernansanz², Javier Olea², \\ Álvaro del Prado ${ }^{2}$ and Ignacio Mártil ${ }^{2}$
}

\begin{abstract}
A complete electrical characterization of hydrogenated amorphous silicon layers (a-Si:H) deposited on crystalline silicon (c-Si) substrates by electron cyclotron resonance chemical vapor deposition (ECR-CVD) was carried out. These structures are of interest for photovoltaic applications. Different growth temperatures between 30 and $200{ }^{\circ} \mathrm{C}$ were used. A rapid thermal annealing in forming gas atmosphere at $200^{\circ} \mathrm{C}$ during 10 min was applied after the metallization process. The evolution of interfacial state density with the deposition temperature indicates a better interface passivation at higher growth temperatures. However, in these cases, an important contribution of slow states is detected as well. Thus, using intermediate growth temperatures $\left(100-150^{\circ} \mathrm{C}\right)$ might be the best choice.
\end{abstract}

Keywords: Hydrogenated amorphous silicon, Photovoltaics, Interfacial state density, Deposition temperature dependencies, Electron cyclotron resonance chemical vapor deposition

\section{Background}

Amorphous silicon layers are of particular interest for photovoltaic applications [1]. In fact, as thin amorphous silicon (a-Si) layers saturate the crystalline silicon (c-Si) surfaces, the formation of recombination centers is avoided, and high quality interfaces are formed, which is of great interest for heterojunction with intrinsic thin layer (HIT) cells [2]. This kind of solar cell consists of a crystalline/amorphous silicon heterojunction, and between both layers, a very thin film $(\sim 5 \mathrm{~nm})$ of intrinsic amorphous silicon (i-a-Si:H) is introduced. The i-a-Si:H layer saturates the silicon surface dangling bonds, and therefore, this surface is passivated. Based on this technology, Panasonic achieved the efficiency world record with $25.6 \%$ for silicon-based solar cells [3]. Plasmaenhanced chemical vapor deposition (PECVD) is the most extended technique used to deposit a-Si:H $[4,5]$. In this technique, the substrate and the plasma are very close, thus the substrate surface could be damaged by plasma bombardment. In this work, we used the

\footnotetext{
* Correspondence: helena@ele.uva.es

'Department of Electronics, University of Valladolid, Paseo Belén, 15, 47011

Valladolid, Spain

Full list of author information is available at the end of the article
}

electron cyclotron resonance chemical vapor deposition (ECR-CVD) technique to deposit the a-Si:H, which is a remote plasma procedure [6] that could reduce the damage to the c-Si surface. Other advantages of ECR-CVD are the possibility of in situ substrate plasma pretreatment [7] and low processing pressure, which permits minimizing the contamination of the growing film [8]. The possibility for scaling-up makes the ECR-CVD a very attractive technique for commercial solar cell fabrication.

As the aim of the intrinsic a-Si:H is the c-Si surface passivation, an interface study in depth is desirable. Previous works showed that the intrinsic amorphous silicon behaves as an insulator at low bias [9], and therefore, it is possible to apply the metal-insulator-semiconductor (MIS) characterization techniques in order to extract information from the a-Si:H/c-Si heterointerface. The density of interface defects can be related to the silicon surface dangling bonds, and its analysis is desirable in order to improve the a-Si:H quality [10].

In this work, we present a characterization of the interface between a-Si:H and c-Si. The results presented in this work support the use of a-Si:H thin films in HIT solar cells. 


\section{Methods}

Metal-intrinsic amorphous silicon-semiconductor structures were fabricated as follows: $100 \mathrm{~nm}$ of intrinsic a-Si:H was deposited by ECR-CVD with an Astex-4500 reactor on n-type $<100>$ silicon wafers with a resistivity of $1-10 \Omega \mathrm{cm}$. Before deposition, the substrates were cleaned by a standard Radio Corporation America (RCA) cleaning [11] process, followed by a dip in diluted HF. The microwave power supply generator was $100 \mathrm{~W}$. The precursor gas used was $19 \mathrm{sccm}$ of $95 \% \mathrm{Ar}+5 \%$ $\mathrm{SiH}_{4}$. Four different deposition temperatures were used (30, 100, 150, and $200{ }^{\circ} \mathrm{C}$ ). Metal electrodes (100 nm $\mathrm{Ti}+200 \mathrm{~nm} \mathrm{Al}$ ) were deposited by e-beam evaporation. An annealing treatment was performed in forming gas atmosphere at $200{ }^{\circ} \mathrm{C}$ during $10 \mathrm{~min}$ by using RTP$600 \mathrm{~S}$ equipment from Modular Process Technology Corp. The area of measured devices was $1.7 \times 10^{-4} \mathrm{~cm}^{2}$. Fourier transform infrared spectroscopy (FTIR) measurements were performed by using a Nicolet MagnaIR 752 spectrometer, in a wave number range from 340 to $4000 \mathrm{~cm}^{-1}$.

As it was said before, due to its low carrier density, a-Si layers behave like insulator layers, so fabricated structures exhibit a similar behavior to MIS capacitors. Therefore, their study was carried out by using the electrical characterization techniques developed for MIS structures. Electrical measurements were carried out putting the sample in a light-tight, electrically shielded box. In order to record electrical parameters at temperatures from liquid nitrogen temperature $(\approx 77 \mathrm{~K})$, samples were cooled in an Oxford DM1710 cryostat. An Oxford ITC 502 temperature controller was used to keep the temperature constant while the electrical measurements are carried out. Current-voltage $(I-V)$ curves were measured using the HP-4155B semiconductor parameter analyzer. Capacitance-voltage $(C-V)$ and conductancevoltage $(G-V)$ measurement setups involved a Keithley 4200SCS semiconductor analyzer. The experimental setup of the conductance transient technique consisted of an HP 3310A function generator to apply the bias pulses, an EG\&G 5206 two-phase lock-in analyzer to measure the conductance, and an HP 54501A digital oscilloscope to record the complete conductance transients. Interface trap density $\left(D_{\text {it }}\right)$ was measured by deep-level transient spectroscopy (DLTS). These measurements were performed using a Boonton 72B capacitance meter, an HP 54501A digital oscilloscope to record the capacitance transients, and an HP 8112A pulse generator to bias the samples from inversion to accumulation. Finally, to obtain the flat-band voltage $\left(V_{\mathrm{FB}}\right)$ transients, a feedback system varied the applied gate voltage accordingly to keep the capacitance at its flat-band value. An Agilent N6700B bias source, a Keithley 6517A electrometer, and a Boonton 72B capacitance meter were used for recording $V_{\mathrm{FB}}$ transients.

\section{Results and Discussion}

In Fig. 1, the characteristic FTIR spectrum of samples deposited at room temperature is shown. Two bands are observed at 640 and $2090 \mathrm{~cm}^{-1}$, corresponding to the $\mathrm{Si}-\mathrm{H}$ wagging mode [12] and the $\mathrm{Si}-\mathrm{H}_{2}$ stretching mode, respectively, as well as the $\mathrm{Si}-\mathrm{H}_{2}$ bending mode in $850 \mathrm{~cm}^{-1}$ and the $\mathrm{Si}-\mathrm{H}_{2}$ scissor mode in $894 \mathrm{~cm}^{-1}$ [13]. The presence of only $\mathrm{Si}-\mathrm{H}$-related bonds reveals high purity film composition. Figure 2a shows $C-V$ measured at room and low temperatures for a sample grown at $100{ }^{\circ} \mathrm{C}$. At room temperature, there is a clear hysteresis, which nearly vanishes at $77 \mathrm{~K}$, thus indicating that the border traps, i.e., the defects located into the insulator in the region close to the interface insulator/oxide, are thermally activated. The same curves are shown in Fig. $2 \mathrm{~b}$ for a sample grown at $200{ }^{\circ} \mathrm{C}$. In this case, hysteresis at room temperature is even greater than that observed in the sample grown at $100{ }^{\circ} \mathrm{C}$. Also, a "shoulder"-shaped feature is clearly seen. Samples grown at the lowest temperatures do not exhibit such feature (see Fig. 3a), so this seems to appear only in samples grown at the highest temperatures, and it is similar to the kink in the $C-V$ response reported in other works $[14,15]$. As growth temperature increases, hysteresis effect and stretch-out of $C-V$ curves increase as well. $C-V$ curves measured at $77 \mathrm{~K}$ (Fig. 3b) show much lower hysteresis than those obtained at room temperature, thus indicating that some traps in the material are frozen at low temperatures [16]. Sample grown at $150{ }^{\circ} \mathrm{C}$ still exhibits appreciable hysteresis at $77 \mathrm{~K}$. As for flat-band voltage values, they increase with growth temperature, reach the maximum value at $150{ }^{\circ} \mathrm{C}$, and then return to the lowest value, as it is shown in Fig. 3b.

Interfacial state densities measured by DLTS are shown in Fig. 4. This technique is time sensitive, so contributions with different time constants are separated and the fast contributions of interface states are clearly

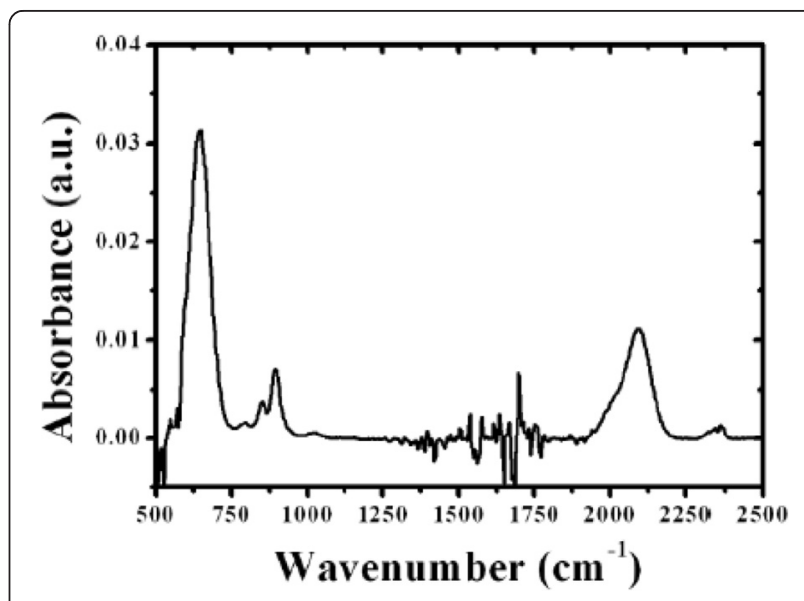

Fig. 1 FTIR spectrum for one sample deposited by ECR-CVD at room temperature. All the bands are related to $\mathrm{Si}-\mathrm{H}$ bonds 


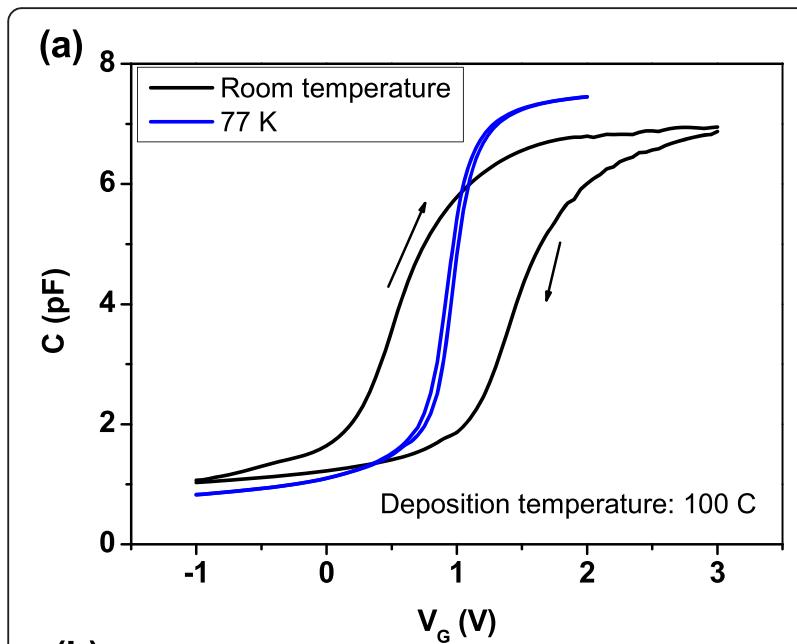

(b)

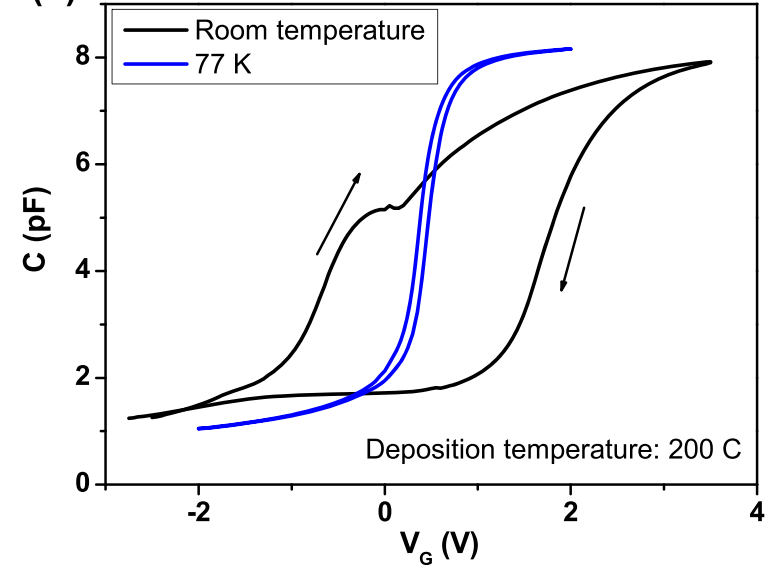

Fig. 2 Capacitance-voltage curves measured at room temperature and at $77 \mathrm{~K}$ corresponding to a temperature deposition of $100{ }^{\circ} \mathrm{C}$ (a) and $200{ }^{\circ} \mathrm{C}$ (b)

distinguished from the slow ones corresponding to defects in the oxide bulk. To obtain the interfacial trap distribution within the band gap, the MIS capacitor is biased just at the limit between depletion and weak inversion, and a pulse high enough to drive the capacitors into the accumulation regime is then applied in order to fill all interfacial traps. The use of a digital oscilloscope allows recording the entire capacitance transients, and therefore, the entire energy spectrum is processed with only one temperature scan. The lowest value of $D_{\text {it }}(2-3 \times$ $10^{11} \mathrm{~cm}^{-2} \mathrm{eV}^{-1}$ ) corresponds to the sample grown at $200{ }^{\circ} \mathrm{C}$. For intermediate growth temperatures, 100 and $150{ }^{\circ} \mathrm{C}, D_{\text {it }}$ values are around $7 \times 10^{11}-1 \times 10^{12} \mathrm{~cm}^{-2} \mathrm{eV}^{-1}$. These values can be considered acceptable. When growth temperature is $30{ }^{\circ} \mathrm{C}, D_{\mathrm{it}}$ increases until it reaches values near $1 \times 10^{13} \mathrm{~cm}^{-2} \mathrm{eV}^{-1}$. This value is too high for technological applications. For comparison, Fig. 4 also depicts the $D_{\text {it }}$ profile corresponding to a sample grown at $30{ }^{\circ} \mathrm{C}$ without a previous cleaning stage by RCA. In this case, $D_{\mathrm{it}}$ values are even higher.

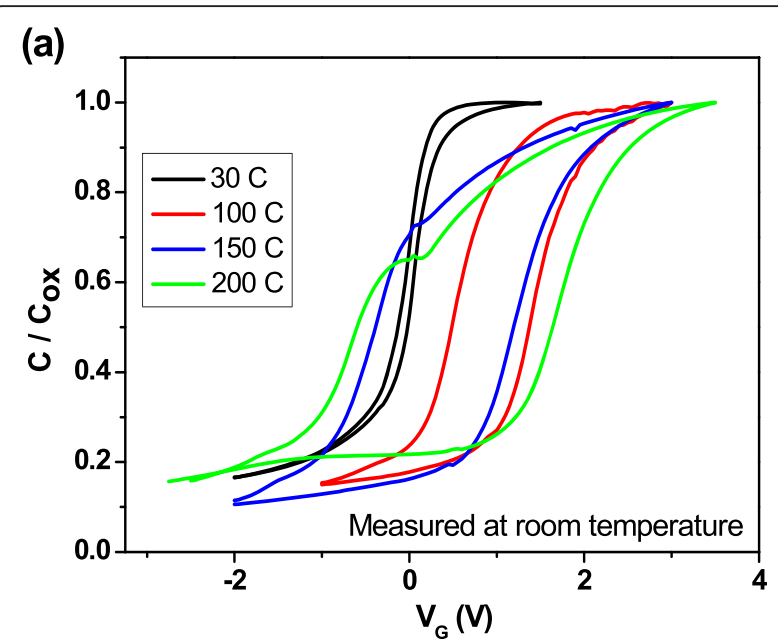

(b)

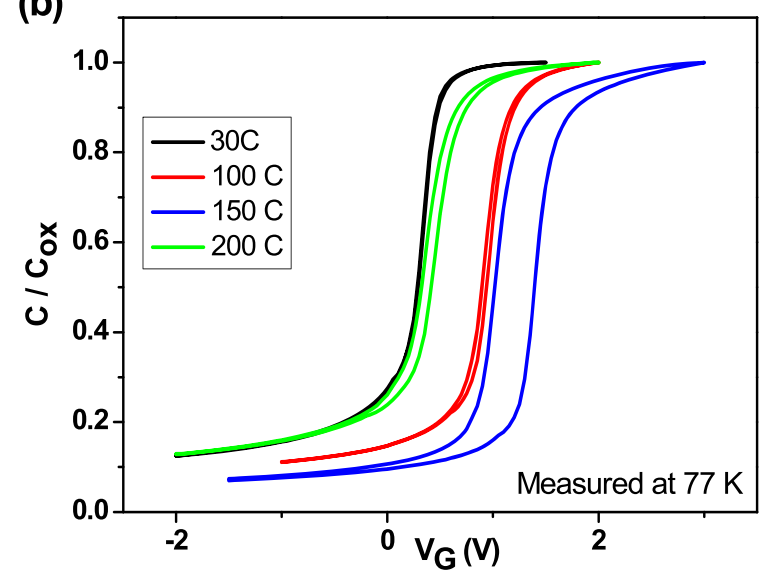

Fig. 3 Capacitance-voltage curves obtained for all deposition temperatures, measured at room temperature (a) and at $77 \mathrm{~K}$ (b)

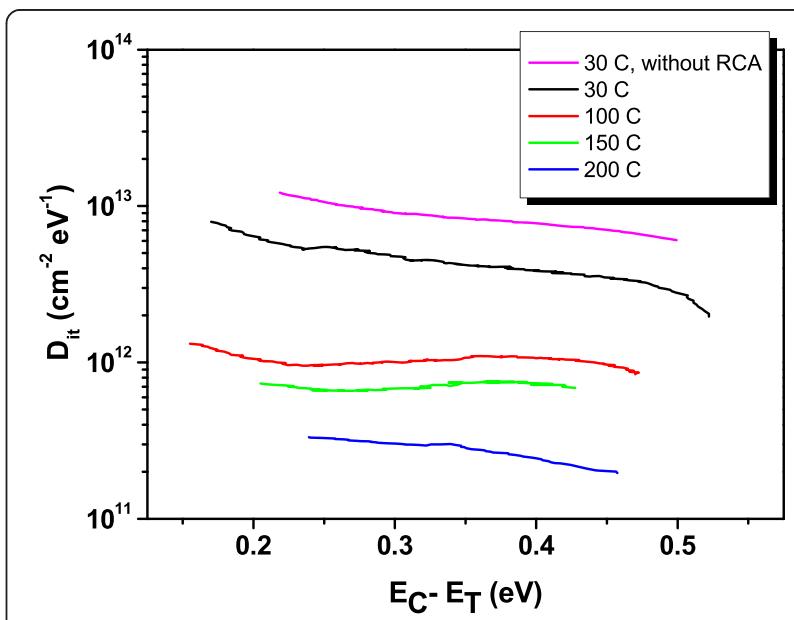

Fig. 4 Interfacial state densities measured by DLTS corresponding to all deposition temperatures. $D_{\text {it }}$ profile obtained for a sample grown at $30^{\circ} \mathrm{C}$ without previous RCA treatment is also shown for comparison 
Border trap densities obtained by means of conductance transient analysis are of the same order of magnitude for the samples grown at 100,150 , and $200{ }^{\circ} \mathrm{C}$. As an illustration, Fig. 5 shows the three-dimensional plot of disorder-induced gap state density ( $\left.N_{\text {DIGS }}\right)$ as a function of the energy and the spatial coordinate for the sample grown at $100{ }^{\circ} \mathrm{C}$. It can be seen that $N_{\text {DIGS }}$ values are in the range of standard MIS devices. On the other hand, for the sample grown at $30{ }^{\circ} \mathrm{C}$, conductance transient amplitudes are below the experimental resolution, so we can conclude that its border trap density is lower than $1 \times 10^{10} \mathrm{~cm}^{-2} \mathrm{eV}^{-1}$. This result agrees well with the high value of $D_{\text {it }}$ measured in this sample, because in general, when border trap density $\left(N_{\text {DIGS }}\right)$ is high, interfacial state density $\left(D_{\mathrm{it}}\right)$ is low [17]. So, for the sample grown at $30{ }^{\circ} \mathrm{C}$, fast traps are preferentially located at the insulator/semiconductor interface, whereas for samples grown at $100-200{ }^{\circ} \mathrm{C}$, fast traps are defects located both at the interface and in the insulator.

Figures 6,7 , and 8 are related to flat-band transient recordings. Figure 6 demonstrates for the sample grown at $100{ }^{\circ} \mathrm{C}$ that there are flat-band transients at room temperature when the sample is previously biased in accumulation or in inversion for a few seconds. In both cases, it is possible to obtain an Arrhenius plot by recording transients at different measurement temperatures. Measurements were carried out at a voltage bias of $0 \mathrm{~V}$, keeping the capacitance at its flat-band value. The flat-band voltage transients are due to trap charging and discharging of defects inside the oxide layer. This mechanism gives rise to variations in flat-band voltage value due to changes in the oxide charge density [18]. As the charge trapping or detrapping inside the oxide is usually tunneling assisted, states located deeper in the oxide capture carriers after those located near the semiconductor/oxide interface, so the $V_{\mathrm{FB}}$ transients obtained

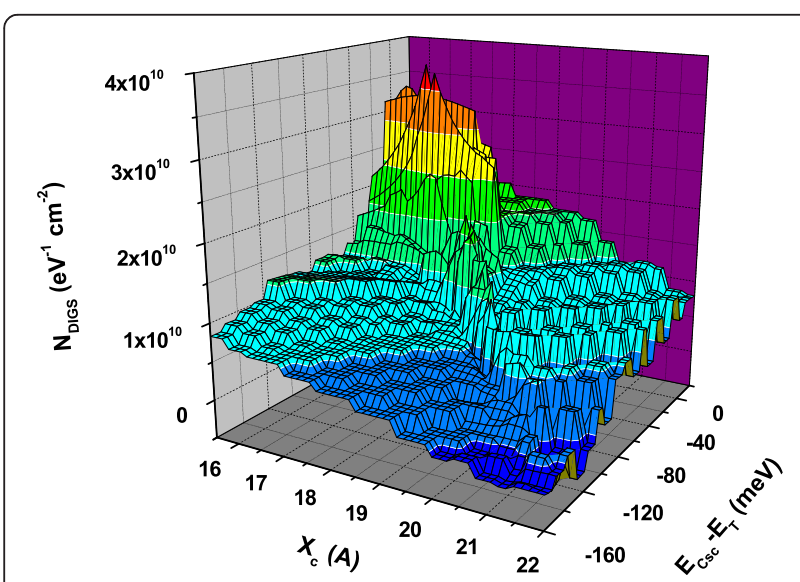

Fig. 5 Border trap three-dimensional distribution of a sample grown at $100^{\circ} \mathrm{C}$

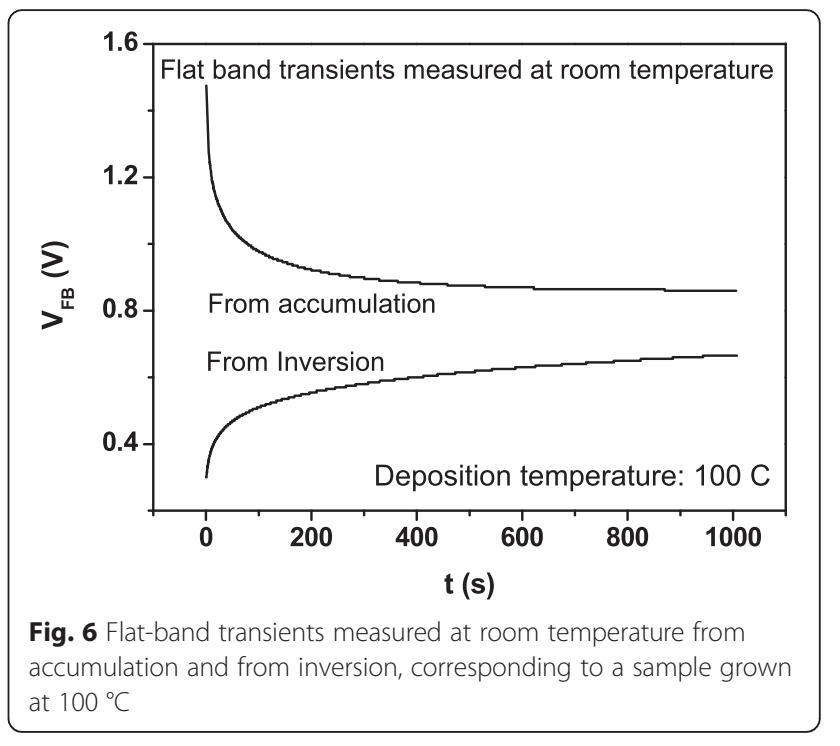

are expected to be slower than the DLTS transients. In Fig. 7 , we can see that the transient amplitudes initially increase with growth temperature, reach their maximum value at $150{ }^{\circ} \mathrm{C}$, and then diminish while transients become faster. In Fig. 8a, we show the flat-band voltage transients recorded at temperatures varying between 195 and $275 \mathrm{~K}$ for the sample grown at $200{ }^{\circ} \mathrm{C}$. The amplitude of transients is thermally enhanced, and the temperature dependence of the transient amplitude follows an Arrhenius plot (Fig. 8b). The linear fit provides an activation energy value of $88 \mathrm{meV}$. Similar values are obtained for all the samples. In the case of high- $\mathrm{k}$ dielectrics, the activation energy has been found to be similar to the soft optical phonon energies [19].

Figure 9 shows current-voltage curves corresponding to the accumulation regime, measured at room temperature and at $77 \mathrm{~K}$. The best behavior corresponds

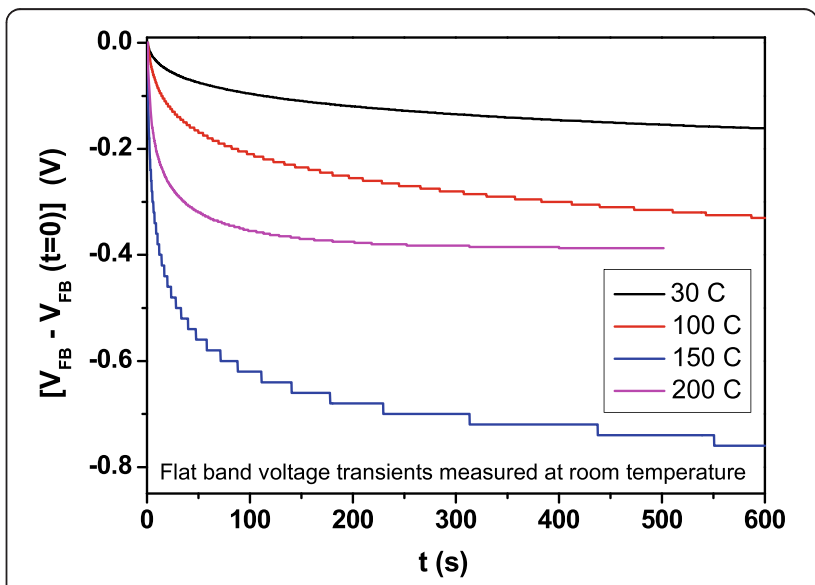

Fig. 7 Flat-band transients from accumulation measured at room temperature corresponding to all deposition temperatures 

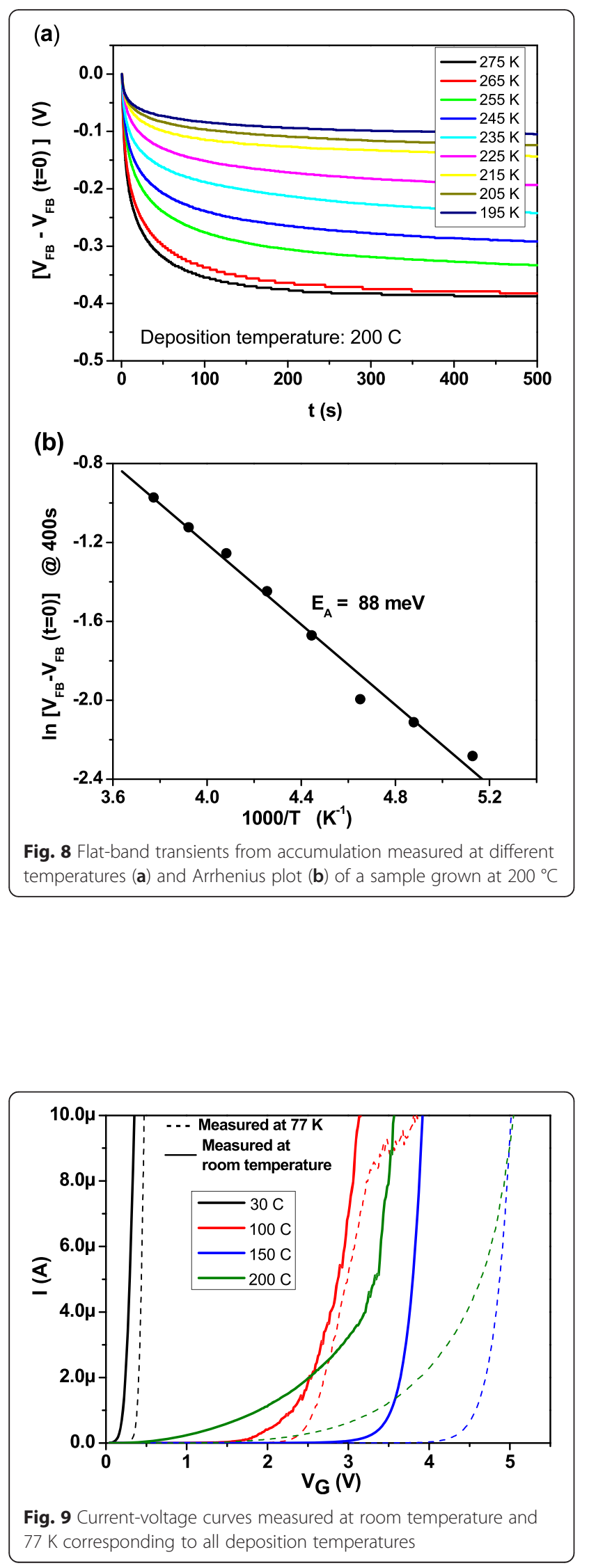

to the $150{ }^{\circ} \mathrm{C}$-deposited sample, with breakdown electric field values corresponding to $2 \mathrm{~mA} / \mathrm{cm}^{2}$ of around 0.35 and $0.45 \mathrm{MV} / \mathrm{cm}$, at room temperature and $77 \mathrm{~K}$, respectively.

Finally, to study in depth the "shoulder"-shaped feature showed in Fig. 2b, some additional measurements have been carried out. When measurement temperature diminishes, the feature also diminishes (see Fig. 10a). In fact, at temperatures lower than 270-280 K, it completely disappears. Focusing on the $C-V$ and $G-V$ curves at room temperature, in the next experiment (Fig. 10b-d), a stair-shaped voltage was used instead of a voltage ramp, with different values of the step width, from $0 \mathrm{~s}$ (which corresponds to the voltage ramp) until $100 \mathrm{~s}$. The absolute value of the increment of the voltage bias was $20 \mathrm{mV}$ in all measurements. Both capacitance and conductance signals exhibit a very different behavior if voltage goes from accumulation to weak inversion or vice versa. In the former case, $C-V$ and $G-V$ curves indicate that generation and recombination through interface trap levels dominate the loss. On the contrary, when voltage bias passes from negative to positive values, $C-V$ curves show a kink and $G-V$ curves show two peaks instead of only one. One of these peaks remains nearly in the same voltage position when measurement conditions are changed. The second one appears at lower values of the voltage and clearly moves to higher values when the measurement time increases. Also, this peak diminishes and nearly disappears for time values of around $100 \mathrm{~s}$.

The shape of $C-V$ and $G-V$ curves when voltage bias values increase can be attributed to the discharge process of slow states located far from the interface, which need high temperature or longer time to release their positive charge. When charge emission takes place, flat-band voltage moves towards more positive values, and so the hysteresis width of $C-V$ curves diminishes. At the same time, the shoulder-shaped feature vanishes. As for $G-V$ curves, the second peak moves to the right and its height diminishes. So, when the samples are driven from weak inversion to accumulation, the loss is due to the generation and recombination through both bulk and interfacial trap levels.

As indicated in Fig. 3a, these phenomena do not appear in samples grown at low temperatures, so the presence of slow traps in the a-Si layer bulk seems to be related to the growth processes carried out at temperatures above $150{ }^{\circ} \mathrm{C}$.

\section{Conclusions}

Interfacial state density values for samples grown at temperatures of $100{ }^{\circ} \mathrm{C}$ and above are in the range of standard devices. Border trap densities and activation 

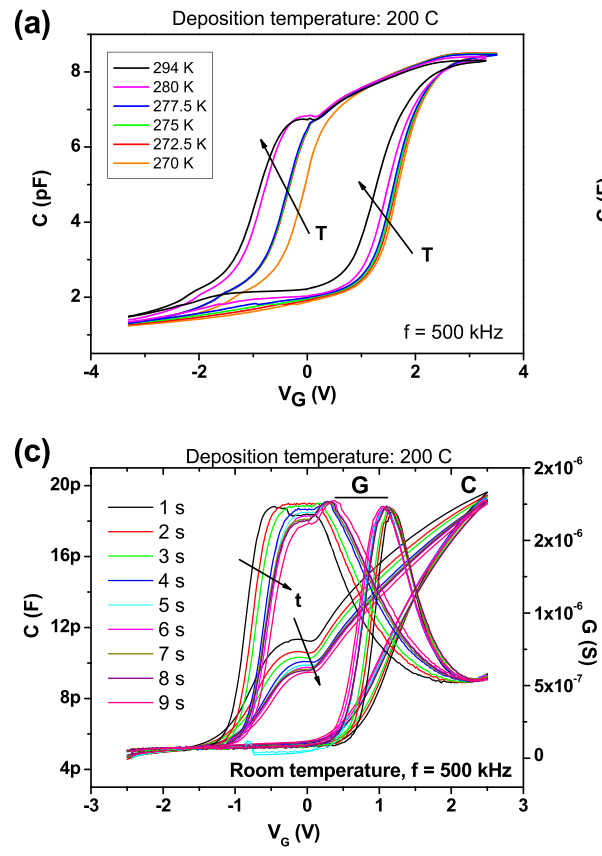
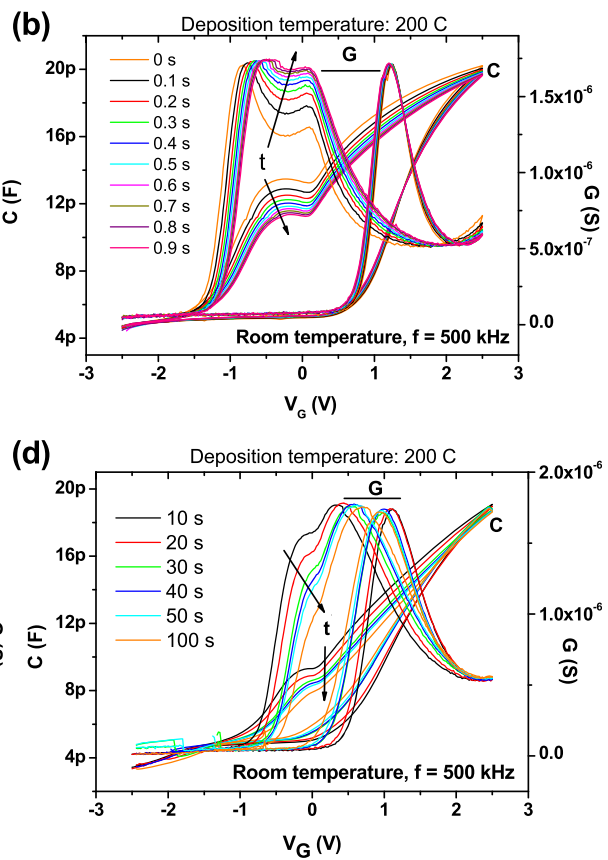

Fig. 10 Capacitance and conductance vs. bias hysteresis loops measured at $500 \mathrm{kHz}$ corresponding to a sample grown at $200{ }^{\circ} \mathrm{C}$, at different temperatures, by using a voltage ramp (a), and at room temperature, by using a stair-shaped voltage, with different values of the step width (b-d). In all cases, the step of voltage bias was $20 \mathrm{mV}$

energy values are in the standard values as well. From our experimental results, the optimal amorphous/crystalline silicon interface is achieved for the highest growth temperature value. However, in samples grown at temperatures of above $150{ }^{\circ} \mathrm{C}$, a significant presence of slow traps in the a-Si layer is detected. In conclusion, to use these kinds of structures in the HIT solar cell application field, growing a-Si layers at $100-150{ }^{\circ} \mathrm{C}$ seems to be the most adequate choice.

\section{Abbreviations}

a-Si:H, hydrogenated amorphous silicon layers; C-Si, crystalline silicon; C-V capacitance-voltage; $D_{\text {it, }}$ interface trap density; DLTS, deep-level transient spectroscopy; ECR-CVD, electron cyclotron resonance chemical vapor deposition; FTIR, Fourier transform infrared spectroscopy; G-V, conductancevoltage; HIT, heterojunction with intrinsic thin layer; i-a-Si:H, intrinsic amorphous silicon; I-V, current-voltage; MIS, metal-insulator-semiconductor; $N_{\text {DIGS, }}$ disorder-induced gap state density; PECVD, plasma-enhanced chemical vapor deposition; RCA, Radio Corporation America; $V_{F B}$, flat-band voltage

\section{Acknowledgements}

The study has been supported by the Spanish TEC2014 under Grant Nos. 52152-C3-3-R and TEC2013-41730-R, funded by the Ministerio de Economía y Competitividad, and the P2013/MAE-2780 funded by the Comunidad de Madrid.

\section{Authors' Contributions}

$\mathrm{HC}$ and IM conceived this study. RGH grew the samples with the help of JO and $A P$. $H G, S D$, and $L B$ characterized the samples. $H C$ wrote the manuscript with the input from all the authors. All authors read and approved the final version of the manuscript.

\section{Competing Interests}

The authors declare that they have no competing interests.

\section{Author details}

'Department of Electronics, University of Valladolid, Paseo Belén, 15, 47011 Valladolid, Spain. ${ }^{2}$ Dpto. Física Aplicada III, Universidad Complutense de Madrid, CEl Campus Moncloa, UCM-UPM, Madrid, Spain.

Received: 26 May 2016 Accepted: 5 July 2016

Published online: 16 July 2016

\section{References}

1. Meiling H, Brockhoff AM, Rath JK, Schropp REl (1998) Hydrogenated amorphous and polycrystalline silicon TFTs by hot-wire CVD. J Non-Crystalline Solids. doi:10.1016/50022-3093(98)00298

2. Tanaka M, Taguchi M, Matsuyama T, Sawada T, Tsuda S, Nakano S, Hanafusa H. Kuwano Y (1992) Development of new a-Si/ e-Si heterojunction solar cells: ACJ-HIT (artificially constructed junction-heterojunction with intrinsic thin-layer). Jpn J Appl Phys 31:3518-22

3. Masuko K, Shigematsu M, Hashiguchi T, Fujishima D, Kai M, Yoshimura N, Yamaguchi T, Ichihashi Y, Yamanishi T, Takahama T, Taguchi M, Maruyama E, Okamoto S (2014) Achievement of more than $25 \%$ conversion efficiency with crystalline silicon heterojunction solar cell. IEEE J Photovoltaics. doi:10.1109/JPHOTOV.2014.2352151

4. Rech B, Kluth O, Repmann T, Roschek T, Springer J, Müller J, Finger F, Stiebig H, Wagner H (2002) New materials and deposition techniques for highly efficient silicon thin film solar cells. Sol Energy Mater Sol Cells 74:439-42

5. Santos JD, Cárabe J, Gandía JJ (2015) Silicon thin-film solar cells at high growth rate under constant power-to-flow ratio plasma conditions. Thin Solid Films. doi:10.1016/j.tsf.2015.11.011

6. Flewit AJ, Milne WI (2005) Low-temperature deposition of hydrogenated amorphous silicon in an electron cyclotron resonance reactor for flexible displays. Proceed of the IEEE. doi:10.1109/JPROC.2005.851533

7. Redondo E, Mártil I, González-Díaz G, Castán H, Dueñas S (2001) Influence of electron cyclotron resonance nitrogen plasma exposure on the electrical characteristics of SiNx:H/InP structures. J Vac Sci Technol B. doi:10.1116/1.1339010

8. García-Hernansanz R, García-Hemme E, Montero D, Olea J, San Andrés E, Del Prado A, Ferrer FJ, Mártil I, González-Díaz G (2016) Limitations of high 
pressure sputtering for amorphous silicon deposition. Mater Res Express. doi:10.1088/2053-1591/3/3/036401

9. García-Hernansanz R, García-Hemme E, Montero D, Del Prado A, Mártil I, González-Díaz G, Olea J (2015) Amorphous/crystalline silicon interface characterization by capacitance and conductance measurements. 10th Spanish Conference on Electron Devices Proceedings (IEEE Conference Publication). INSPEC Accession Number: 15060343. doi:10.1109/CDE.2015. 7087502

10. Schulze TF, Beushausen HN, Leendertz C, Dobrich A, Rech B, Korte L (2010) Interplay of amorphous silicon disorder and hydrogen content with interface defects in amorphous/crystalline silicon heterojunctions. Appl Phys Lett. doi:10.1063/1.3455900

11. Kern W, Puotinen D (1970) Cleaning solutions based on hydrogen peroxide for use in silicon semiconductor technology. RCA Rev 31:187-206

12. Mahan AH, Gedvilas LM, Webb JD (2000) Si-H bonding in low hydrogen content amorphous silicon films as probed by infrared spectroscopy and $\mathrm{x}$ ray diffraction. J Appl Phys. doi:10.1063/1.372073

13. Girginoudi D, Tsiarapas C, Georgoulas N (2011) Properties of a-Si:H films deposited by RF magnetron sputtering at $95^{\circ} \mathrm{C}$. Appl Surf Sci. doi:10.1016/j. apsusc.2010.11.115

14. Masson P, Autran JL, Houssa M, Garros X, Leroux C (2002) Frequency characterization and modeling of interface traps in $\mathrm{HfSi}_{\mathbf{x}} \mathrm{O}_{\mathrm{y}} / \mathrm{HfO}_{2}$ gate dielectric stack from a capacitance point-of-view. Appl Phys Lett 81:3392-4

15. Stesmans A, Afanas'ev W (2003) Si dangling-bond-type defects at the interface of (100)Si with ultrathin $\mathrm{HfO}_{2}$. Appl Phys Lett 82:4074-6

16. Dueñas S, Castán H, Barbolla J, Kukli K, Ritala M, Leskelä M (2003) Conductance transient, capacitance-voltage and deep-level transient spectroscopy characterization of atomic layer deposited hafnium and zirconium oxide thin films. Solid State Electron 47(2003):1623-9

17. García H, Dueñas S, Castán H, Bailón L, Kukli K, Aarik J, Ritala M, Leskelä M (2008) Identification of spatial localization and energetic position of electrically active defects in amorphous high-k dielectrics for advanced devices. J Non-Crystalline Solids 354:393-8

18. Dueñas S, Castán H, García H, Gómez A, Bailón L, Kuli K, Aarik J, Ritala M, Leskelä M (2008) Comparative study of flatband voltage transients on highk dielectric-based metal-insulator-semiconductor capacitors. J Electrochem Soc. doi:10.1149/1.2975828

19. Dueñas S, Castán H, García H, Bailón L, Kukli K, Hatanpää T, Ritala, Leskelä M (2007) Experimental observations of temperature-dependent flat band voltage transients on high-k dielectrics. Microelectron Reliab. doi:10.1016/j. microrel.2007.01.080

\section{Submit your manuscript to a SpringerOpen ${ }^{\circ}$ journal and benefit from:}

- Convenient online submission

- Rigorous peer review

- Immediate publication on acceptance

- Open access: articles freely available online

- High visibility within the field

Retaining the copyright to your article 